\title{
Meta-Analysis of the Correlation between Emotional Intelligence and Life Satisfaction
}

\author{
Hartanto \\ Doctoral Student Gadjah Mada University, Indonesia, hartanto@mail.ugm.ac.id \\ Avin Fadila Helmi \\ Faculty of Psychology, Gadjah Mada University, Indonesia, avinpsi@ugm.ac.id
}

\begin{abstract}
This meta-analysis research aims to find the true correlation (true effect) between emotional intelligence and life satisfaction. In addition, it maps the dispersion of the correlation effect of the study after being corrected. This research consisted of 35 studies and involved 12,805 subjects. The estimator for this research used Hunter-Schmidt (HS). 92 studies were collected, and 35 met the criteria; they were analyzed by the correction method of sampling and measurement error. From the analysis, we found that the correlation between emotional intelligence variables with life satisfaction was moderately positive. The $\mathrm{Q}$ test was proven significant with the $\mathrm{I}^{2}$ value, also showing high heterogeneity of data. After sampling and measurement correction, the correlation mean effect is 0.349 and 0.412 , respectively. Both of the confidence interval predictions do not contain zero (0.28-0.41 barebone analysis; 0.33-0.47 measurement correction). Egger's test found that there was no correlation between standard error and outcome effect $(\mathrm{p}=0.35$ and $\mathrm{p}=0.299)$, implying that no reporting bias across studies. These results reinforce that emotional intelligence influences life satisfaction with cross-cultural, cross-ages samples.
\end{abstract}

Keywords: emotional intelligence, life satisfaction, meta-analysis, systematic review, intelligence

\section{INTRODUCTION}

Peter Salovey and John Mayer first popularized the term "emotional intelligence" around 1990, and it was then published by Goleman (1995) in his book. Mayer also added that the source of emotional intelligence is the emotions themselves, which will surely experience changes when the individual is related to other individuals (Mayer, Caruso \& Salovey, 2000). Emotional intelligence is intelligence that influences an individual's ability to assess his emotions and the emotions of others concerning problem-solving (Bar-On, 2010; Saricam, Celik \& Coskun, 2015). In the education field, students that possesses high emotional intelligence will also be more motivated and have the skills to collaborate with other individuals (Parker, Saklofske, Wood, \& Collin, 2009). Emotional intelligence is divided into five domains (Salovey \& Mayer, 1990): empathy, self-knowledge, regulation of emotional conditions, self-motivation, and regulation of interpersonal relationships. Empathy is our ability to understand what is being thought by other individuals through observation of verbal and non-verbal behavior. In short, empathy is closely related to the sensitivity to feel what other people feel. Selfknowledge is related to how far we understand our emotional state. Usually, individuals who can predict the condition of their emotions can distance themselves from emotional outbursts, whether in a positive or negative state. Self-motivation is related to emotional integration to achieve goals. Emotional regulation aims to pull up negative emotions or cultivating positive emotions so that they are stable and constant for future event. Finally, interpersonal relationships are related to negotiating and persuading the emotional states of other individuals.

The relation between academic achievement and emotional intelligence is relatively high (Hogan et al., 2010; Suleman et al., 2019), so it can be concluded that emotional intelligence contributes to student

Citation: Hartanto., \& Helmi, A. F. (2021). Meta-analysis of the correlation between emotional intelligence and life satisfaction. Anatolian Journal of Education, 6(2), 63-74. https://doi.org/10.29333/aje.2021.626a 
success in academic achievements, not just intelligence quotient. Study meta-analysis from MacCann et al (2020) using total sample 42,529 from 158 citation also state that emotional intelligence has strong correlation with academic succes. Moreover MacCann state that an individual who has a high emotional intelligence quotient can build communicative skills or be able to work in a team and have high regulation acedemic emotion. In other word, an individual who has good academic grades might also be able to control his emotions in terms of intrapersonal relationships. Di Fabio and Palazzeschi (2009) found that emotional intelligence, not just IQ, has an essential role in one's career. Varatharaj and Vasantha (2012) also explained that emotional intelligence is needed to balance personal and professional relationships. Without the presence of an individual's emotional intelligence, it will not be easy to maintain a balance between a private nature and a professional relationship between colleagues. Emotional intelligence has also been shown to be positively correlated with positive coping (Landa et al., 2009; Beauvais et al., 2011), work relationship (Alavi et al., 2017), work productivity (Ahuja, 2011), and even life satisfaction (Carvalho, Guerrero, \& Chambel, 2018). RuizAranda et al. (2013) also found that groups of students who had higher emotional intelligence than other groups reported lower levels of stress and resistance to stressful conditions.

Emotional intelligence turned out to be very closely related to life satisfaction as a condition of the results of emotionally intelligent individuals. This evidence was obtained from several studies involving variables of emotional intelligence and life satisfaction index (Gallagher \& Vella-Brodick, 2008; Hahn, Frese, Binnewies, \& Schmitt, 2011; Di Fabio \& Kenny, 2016). The definition of life satisfaction is a reflection of comparing and contrasting the current situation with expectations for life (Ignat \& Clipa, 2012), including aspects of spirituality, health, income, and work (Diener \& BiswasDiener, 2008; Disabato et al., 2015). At first glance, this concept is the same as the ideal self and selfexpectancy; the distance that exists between the two selves is reviewed and analyzed subjectively, and the results that come out define what life satisfaction is. This evaluation involves cognitive and emotional aspects (Di Fabio \& Kenny, 2019; Maddux, 2018). This research focuses on life satisfaction with cognitive facets from Diener and his derivative theories. Its characteristics are a cognitive effort in interpreting life and conducting cognitive evaluations and reflections obtained from all sectors of life (Ozsoy, Uslu, \& Ozturk, 2014), including work and other interpersonal relationships (Yiğit et al., 2011).

Both in Eastern and Western culture, research on the relationship between emotional intelligence and life satisfaction always seems linear and positive. It means that in both cultures, an individual with high emotional intelligence will have a high index of life satisfaction (Kong, Zhao \& You, 2012; Runcan \& Iovu, 2013). However, research on emotional intelligence and life satisfaction has never been systematically reviewed, so a holistic conclusion cannot be obtained by considering each correlation coefficient value. This gap may lead to minimize how importance emotional intelligence for well being, especially in adolescent and school.

This research was conducted to fill the gap and obtain the outcome of the relationship between emotional intelligence and life satisfaction through a systematic review. Meta-analysis is the only analysis technique that can "capture" the relationship patterns of many quantitative studies, from the $r$ coefficient, t-value, F-value, alpha-value, and mean and standard deviations. The output obtained later, regarding the relationship of emotional intelligence and life satisfaction, can be a reference to build a theoretical model (Aksayli, Sala \& Gobet, 2019).

\section{Meta-Analysis}

Variations that arise in social science often lead to conflict between studies in examining the dynamics of existing phenomena. Conducting systematic reviews helps obtain accurate data regarding the study of variables used to support the theory (building block theory). Meta-analysis is a quantitative method 
for checking the variance of research. Card (2015) defines meta-analysis as a systematic review involving multiple studies so that a study will act as a unit of a subject.

In the meta-analysis, there are several commonly used approaches, namely the estimator approach (Langan et al, 2015). These methods used almost the same formulation to look for the effects in a meta-analysis, but only the Hunter-Schmidt approach used a technique to not correct the bias effect size before determining the mean effect size (weighting the sample size in each effect size) (Johnson et al., 1995). According to Diener et al. (2009), the Hunter-Schmidt method is considered to be less biased in random effect calculation than the Hedges method. Therefore, we decided to use the approach of Hunter-Schmidt in conducting meta-analysis.

\section{METHOD}

\section{Research Design}

Systematic review is part of the quantitative method. The criteria used for the meta-analysis approach are: 1) Quantitative correlation research between emotional intelligence variables and life satisfaction variables; 2) Emotional intelligence as the independent variable and life satisfaction as the dependent variable; 3) The data displayed in the article is sufficient for a meta-analysis. Sequence step for metaanalysis are : 1) After being selected using the above criteria, there were 35 studies that were feasible to proceed for a meta-analysis. 2) Compute data ( $\mathrm{r}$ coefficient) using the HS estimator, for sampling errors (bare-bone analysis; sampling errors). 3) Next step is to compute measurement errors (individual correcting; measurement error) however due to different scale were used in emotional intelligence before individual correction carried out, we using Mosier formula for composite reliability, hence the reliability for each scale would be in the same scale. 4) After measurement correction was done, forest plot then produced to gave the research data visualization in single set axis. 5) Final step is analyze reporting and publication bias using Egger's regression test. All analysis is done with the help of several $\mathrm{R}$ packages ( $\mathrm{R}$ Core Team, 2018).

\section{Data Collection}

The search was carried out by several proxy databases, including EBSCO, Scopus, and PsycINFO, as well as through the National Library and the UGM Library. The keywords used are emotional intelligence, emotional quotient, life satisfaction, subjective well-being, and cognitive facet well-being. The database search found 92 study units involving emotional intelligence as an independent variable and life satisfaction as the dependent variable. The studies were obtained from year range 2005 to 2019.

\section{Data Analysis}

To optimize the findings from the study, so that data from several studies can still be used, three packages are decided for analysis. For example, some of the study units in the above studies have scores on each subscale, which means the correlation coefficient (r) and reliability coefficient (rxx; ryy) have individual/respective scores and must be transformed so that they are eligible to be used in the meta-analysis. This score transformation ability was obtained from the psychmeta (Dahlke \& Wiernik, 2019) package using the formula from Mosier (1943) with the classical test approach. The Meta package (Schwarzer, 2019) is used to produce the Fisher zcor transformation data table. Last, sampling and artifact correction is done using the metafor package (Viechtbauer, 2019).

The effect size is the main data for meta-analysis. However, due to the variation occurring between the studies, we decided to use the random effect approach. In the random effect approach, an average effect size interpretation must be accompanied by a prediction interval that does not contain zero (Riley, Higgins, \& Deeks, 2011). 
Table 1

Research study sample, correlation coefficient and reliability coefficient

\begin{tabular}{|c|c|c|c|c|c|c|}
\hline No & Researcher Names & $\mathrm{N}$ & Sample & rxx & ryy & $\mathrm{r}$ \\
\hline 1 & Extremera \& Berrocal (2005) & 184 & College Student & 0.88 & 0.82 & 0.52 \\
\hline 2 & Gannon \& Ranzijin (2005) & 191 & College Student & 0.92 & 0.83 & 0.49 \\
\hline 3 & Gallagher \& Vella-Brodrick (2008) & 267 & College Student & 0.90 & 0.89 & 0.41 \\
\hline 4 & Por, Bariball, \& Fizpatrick (2011) & 130 & Adult & 0.82 & 0.86 & 0.27 \\
\hline 5 & Rey, Extremera \& Pena (2011) & 316 & Teenager & 0.85 & 0.81 & 0.34 \\
\hline 6 & Schute \& Malaouff (2011) & 122 & College Student & 0.87 & 0.89 & 0.47 \\
\hline 7 & Habib, Riaz \& Akram (2012) & 300 & Adult & 0.87 & 0.79 & 0.35 \\
\hline 8 & Ignat \& Clipa (2012) & 196 & Adult & 0.72 & 0.87 & 0.23 \\
\hline 9 & James, Bore \& Zito (2012) & 150 & College Student & 0.87 & 0.86 & 0.43 \\
\hline 10 & Kong, Zhao \& You (2012) & 678 & Adult & 0.89 & 0.82 & 0.27 \\
\hline 11 & Koydemir dkk (2012) (India) & 232 & College Student & 0.86 & 0.81 & 0.24 \\
\hline 12 & Koydemir dkk (2012) (German) & 170 & College Student & 0.86 & 0.76 & 0.31 \\
\hline 13 & Kong, Zhao \& You (2012) & 489 & College Student & 0.89 & 0.8 & 0.25 \\
\hline 14 & Ozyer, Azizoglu, \& Fahrevaa (2012) & 114 & Adult & 0.90 & 0.87 & 0.67 \\
\hline 15 & Liu, Wang \& Lu (2013) & 263 & Adult & 0.85 & 0.77 & 0.21 \\
\hline 16 & Kong \& Zhao (2013) & 620 & College Student & 0.89 & 0.82 & 0.29 \\
\hline 17 & Runcan \& Bogdan (2013) & 131 & College Student & 0.82 & 0.68 & -0.32 \\
\hline 18 & Diekola \& Adebayo (2014) & 300 & Adult & 0.87 & 0.82 & 0.14 \\
\hline 19 & Wang \& Kong (2014) & 321 & Adult & 0.85 & 0.85 & 0.22 \\
\hline 20 & Sun, Wang \& Kong (2014) & 424 & College Student & 0.85 & 0.78 & 0.29 \\
\hline 21 & Cazan \& Nastasa (2015) & 91 & College Student & 0.88 & 0.82 & 0.38 \\
\hline 22 & Mehta \& Mehta (2015) & 150 & Adult & 0.90 & 0.82 & 0.56 \\
\hline 23 & Escoda \& Alegre (2016) & 2223 & College Student & 0.92 & 0.84 & 0.53 \\
\hline 24 & Saricam, Celik \& Coskun (2015) & 478 & Adult & 0.89 & 0.85 & 0.47 \\
\hline 25 & Farhan \& Ali (2016) & 300 & Adult & 0.88 & 0.81 & 0.23 \\
\hline 26 & Beduna \& Peruna-McGovern (2016) & 144 & Teenager & 0.89 & 0.87 & 0.40 \\
\hline 27 & Chen, Peng \& Fang (2016) & 360 & Adult & 0.89 & 0.80 & 0.45 \\
\hline 28 & Sahrai, Alipour \& Alipour (2016) & 130 & Adult & 0.84 & 0.78 & 0.48 \\
\hline 29 & Extremera \& Rey (2016) & 721 & College Student & 0.89 & 0.84 & 0.13 \\
\hline 30 & Delhom dkk (2017) & 215 & Adult & 0.90 & 0.89 & 0.33 \\
\hline 31 & Afolabi \& Balogun (2017) & 273 & College Student & 0.80 & 0.72 & 0.32 \\
\hline 32 & Geng (2018) & 365 & College Student & 0.91 & 0.79 & 0.25 \\
\hline 33 & Blasco-Belled (2019) & 749 & Teenager & 0.86 & 0.86 & 0.36 \\
\hline 34 & Tang-Huang \& Lin Lee (2019) & 260 & College Student & 0.88 & 0.89 & 0.44 \\
\hline 35 & Kong dkk (2019) & 748 & Adult & 0.89 & 0.82 & 0.31 \\
\hline
\end{tabular}

rxx = reliability variable emotional intelligence; ryy = reliability life satisfaction 
Table 2

Coefficient correlation to Fisher Z

\begin{tabular}{|c|c|c|c|c|c|c|}
\hline Study & $\mathrm{r}$ & $\mathrm{N}$ & zcor & $\mathrm{W}(\%)$ & Lower CI & Upper CI \\
\hline 1 & 0.52 & 184 & 0.58 & 2.7 & 0.43 & 0.72 \\
\hline 2 & 0.49 & 191 & 0.54 & 2.8 & 0.39 & 0.68 \\
\hline 3 & 0.41 & 267 & 0.44 & 2.9 & 0.31 & 0.56 \\
\hline 4 & 0.27 & 130 & 0.28 & 2.6 & 0.14 & 0.45 \\
\hline 5 & 0.34 & 316 & 0.35 & 3.0 & 0.24 & 0.46 \\
\hline 6 & 0.47 & 122 & 0.51 & 2.5 & 0.33 & 0.69 \\
\hline 7 & 0.35 & 300 & 0.37 & 2.9 & 0.25 & 0.48 \\
\hline 8 & 0.23 & 196 & 0.23 & 2.8 & 0.09 & 0.38 \\
\hline 9 & 0.43 & 150 & 0.46 & 2.6 & 0.32 & 0.62 \\
\hline 10 & 0.27 & 678 & 0.28 & 3.1 & 0.21 & 0.35 \\
\hline 11 & 0.24 & 232 & 0.24 & 2.8 & 0.12 & 0.37 \\
\hline 12 & 0.31 & 170 & 0.32 & 2.7 & 0.17 & 0.47 \\
\hline 13 & 0.25 & 489 & 0.26 & 3.1 & 0.17 & 0.34 \\
\hline 14 & 0.67 & 114 & 0.81 & 2.5 & 0.62 & 0.98 \\
\hline 15 & 0.21 & 263 & 0.21 & 2.9 & 0.09 & 0.33 \\
\hline 16 & 0.29 & 620 & 0.30 & 3.1 & 0.22 & 0.38 \\
\hline 17 & -0.32 & 131 & -0.33 & 2.6 & -0.53 & -0.16 \\
\hline 18 & 0.14 & 300 & 0.14 & 2.9 & 0.03 & 0.25 \\
\hline 19 & 0.22 & 321 & 0.22 & 3.0 & 0.11 & 0.33 \\
\hline 20 & 0.29 & 424 & 0.30 & 3.0 & 0.20 & 0.39 \\
\hline 21 & 0.38 & 91 & 0.40 & 2.3 & 0.19 & 0.61 \\
\hline 22 & 0.56 & 150 & 0.63 & 2.6 & 0.47 & 0.79 \\
\hline 23 & 0.53 & 2223 & 0.59 & 3.3 & 0.55 & 0.63 \\
\hline 24 & 0.47 & 478 & 0.51 & 3.1 & 0.42 & 0.60 \\
\hline 25 & 0.23 & 300 & 0.23 & 2.9 & 0.12 & 0.35 \\
\hline 26 & 0.4 & 144 & 0.42 & 2.6 & 0.26 & 0.59 \\
\hline 27 & 0.45 & 360 & 0.48 & 3.0 & 0.38 & 0.59 \\
\hline 28 & $\begin{array}{l}0.48 \\
\end{array}$ & 130 & 0.52 & 2.6 & 0.35 & 0.70 \\
\hline 29 & 0.13 & 721 & 0.13 & 3.2 & 0.06 & 0.20 \\
\hline 30 & 0.33 & 215 & 0.34 & 2.8 & 0.21 & 0.48 \\
\hline 31 & 0.32 & 273 & 0.33 & 2.9 & 0.21 & 0.45 \\
\hline 32 & 0.25 & 365 & 0.26 & 3.0 & 0.15 & 0.36 \\
\hline 33 & 0.36 & 749 & 0.38 & 3.2 & 0.31 & 0.45 \\
\hline 34 & 0.44 & 260 & 0.47 & 2.9 & 0.35 & 0.59 \\
\hline 35 & 0.31 & 748 & 0.32 & 3.2 & 0.25 & 0.39 \\
\hline
\end{tabular}

\section{FINDINGS}

\section{Sampling Error Correction}

Hunter and Schmidt (2015) delivered a bare-bone correlation meta-analysis and artifact measurement correction using Fisher $\mathrm{z}$ to $\mathrm{r}$ transformations to calculate the analysis. The mean value of the coefficient must be calculated taking into account the errors that might occur during the sampling process. Based on the results of the analysis, it was found that the correction of sampling error 
received an estimation of 0.348 , which is very clear that the correlation between emotional intelligence and life satisfaction is moderately positive, and the analysis-obtained $\mathrm{T}^{2}$-value (tau-square) is 0.0207 , while $\mathrm{T}$ is 0.144 .

$\mathrm{T}^{2}$ is the observed coefficient of variance between studies where $\tau$ (tau) itself is an estimate of the standard deviation of the effects of the entire study (correlation). Both $\mathrm{T}^{2}$ and $\mathrm{T}$ values reflect the degree of heterogeneity of the data. According to Mikolajewicz and Komarova (2019), data from meta-analysis research is expected to be heterogeneous because it can provide information about factors that influence the study (biological factors or methodology use). The analysis continued by looking for Q-values (389.2091; $\mathrm{p}<0.001)$, which proved to be statistically significant. The coefficient of $\mathrm{Q}$ is the sum-weighted difference between the observed effect and the mean-weighted effect and indicates the significance of the variance of the study effect. After that, the $\mathrm{H}^{2}$-value indicates the amount of heterogeneity, where $\mathrm{H}^{2}=1$, indicating homogeneous data $\left(\mathrm{H}^{2}=10.60\right)$. From the $\mathrm{H}^{2}$-value, the transformation is performed to obtain the interval of confidence in heterogeneity known as the $\mathrm{I}^{2}$ value. $I^{2}$ ranges from $0-100 \%(25 \%=$ low heterogeneity, $50 \%=$ substantive heterogeneity, $75 \%<$ high heterogeneity). From the analysis results obtained, $\mathrm{I}^{2}$ value $>75 \%(90.56 \%)$, where the variation was caused by the study and the rest by other factors. The above results show the high heterogeneity of this research.

Furthermore, based on the analysis-obtained prediction of error sampling values (variants due to side errors), the correlation variant is equal to 0.00212 , while the estimation of the correlation variant after sampling correction or correlation variant without error sampling is at 0.0186 . The level of CI (see table 3 ) moves from the range $0.28-0.41$. Of the 35 studies, only one study has a negative correlation, and from the forest plot, the graph does not include zero, indicating all studies were significant (Hak et al., 2016). It can also be seen from the range of levels of confidence that the studies were closely related, which can be interpreted as the significance of the p-value according to the sample size (representative).

\section{Measurement Error Correction}

After sampling correction, Hunter and Schmidt (2015) suggest that the artifact correction is not only at the sampling level but can also be done on measurements. Dahlke and Wiernick (2019) use the term "individual-artifact correcting," which refers to corrections made on each study measurement. After adding the reliability value from each study, the analysis obtained the estimated effect correlation of 0.412 and variant effect after being corrected was 0.0262 . Variance caused by measurement error is 0.00291 , indicating that measurement error has less impact to reducing the correlation coefficient. Finally, the results of the estimation of variance from correlations that have been corrected after removing variance errors are $0.0233\left(\mathrm{~T}^{2}\right) . \mathrm{H}^{2}$ and $\mathrm{I}^{2}$ statistical test values after measuring corrections were obtained at $8.70(\mathrm{H}>1)$ and $88.5 \%$ (> 75\%), indicating high-level heterogeneity. Results were still significant after measuring the corrections in 35 studies despite the high variance of each study's effect with a mean (disperse from the mean). 
Table 3

Corrected sampling and corrected measurement

\begin{tabular}{llll}
\hline $\mathrm{N}$ & 12805 & $\mathrm{~N}$ & 12805 \\
\hline $\mathrm{k}$ & 35 & $\mathrm{k}$ & 35 \\
\hline $\mathrm{r}$ & 0.349 & $\mathrm{r}$ & 0.412 \\
\hline $\mathrm{sd} \mathrm{r}$ & 0.144 & $\mathrm{sd} \mathrm{rc}$ & 0.162 \\
\hline $\mathrm{se} \mathrm{r}$ & 0.0244 & se rc & 0.0273 \\
\hline sd e & 0.046 & sd ec & 0.0539 \\
\hline sd res & 0.137 & sd resc & 0.152 \\
\hline ci ll - ci ul & $0.28-0.41$ & ci ll - ci ul & $0.33-0.47$ \\
\hline
\end{tabular}

The use of $\mathrm{I}^{2}$ as a statistical test to measure heterogeneity in meta-analysis has several advantages compared to the Cochrane Q-Test value, which is more robust to the number of studies (Higgins, Thompson, Deeks, \& Altman, 2003). Nevertheless, the use of $\mathrm{I}^{2}$ alone to determine the degree of heterogeneity is considered inappropriate and must be accompanied by other measurement indices (Borenstein, Higgins, Hedges, \& Rothstein, 2017). Moreover, detection for bias especially reporting bias were done using Egger's Test (Egger et al, 1997). Also this method was preferable in many meta studies (Sterne et al, 2011; Sedgwick, 2013). The p value for Egger's test in both method correction above were $\mathrm{p}=0.3653$ and $\mathrm{p}=0.2995$, respectively. The result indicate that there was no correlation between predictor standard error and observed effect outcome. This is also can be conclude that there was no evidence to reject the null hypotesis and therefore no bias exist in meta studies. After all, it can be seen that all indices in the statistical analysis are satisfactory

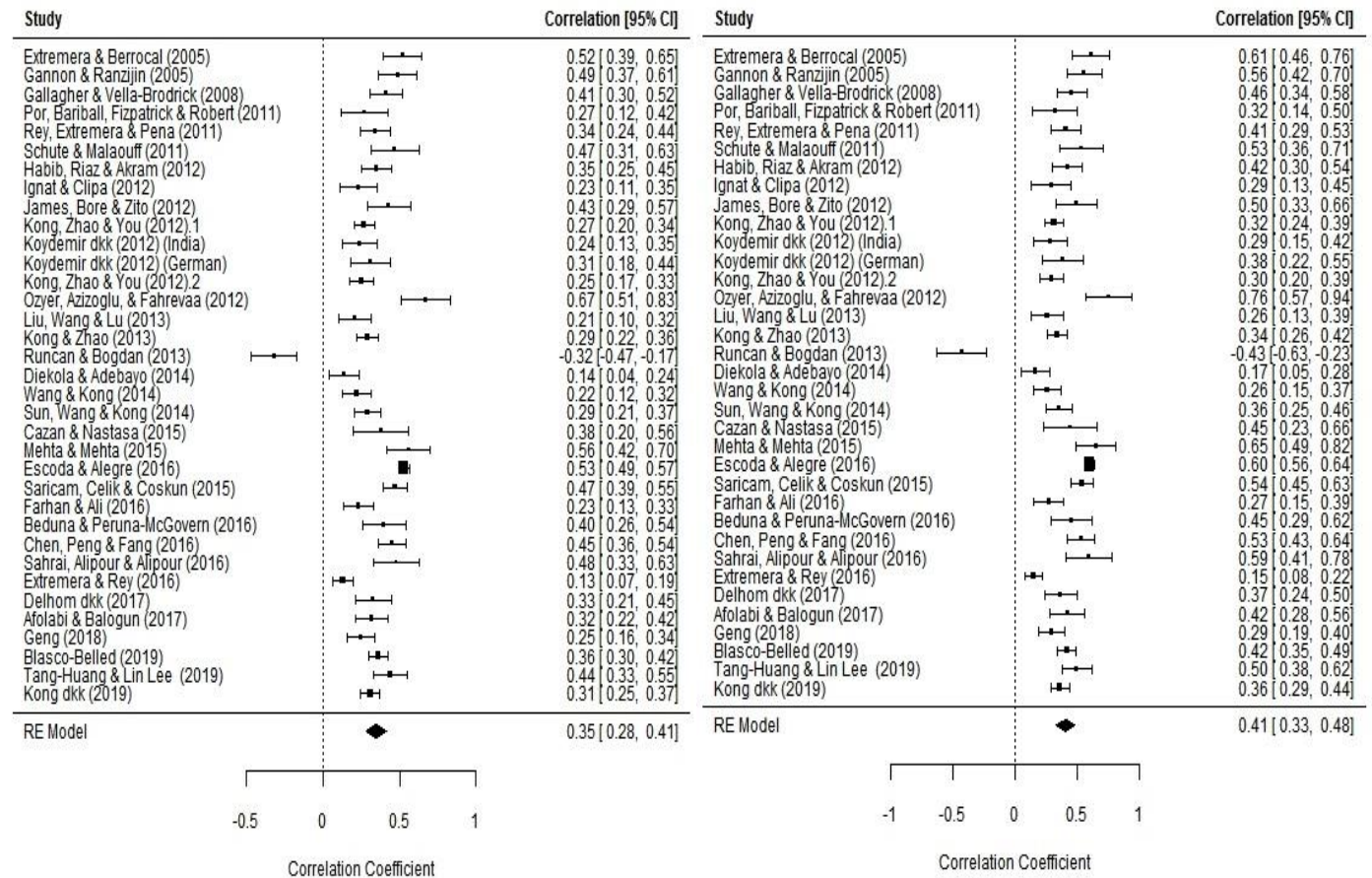

Figure 1

Forest plot sampling corrected and measurement corrected 


\section{DISCUSSION AND SUGGESTIONS}

From the results, we concluded that there is indeed a moderate correlation between emotional intelligence and life satisfaction, as shown with the $\mathrm{z}$-value of 12.03 and r-value of 0.349 in corrected sampling and r-value of 0.412 in corrected artifact. However, if the results yield an interval prediction range restriction too wide between the two method corrections and also contain zero, the next analysis including moderator (group) is necessary (Aguinis, Sturman, \& Pierce, 2008). The majority of the subjects of this study are teenagers and students; however, the results prove that their emotional intelligence has been formed (mature) and is able to influence the life satisfaction variables of cognitive facets. These findings were useful for the education system, where promoting emotional intelligence can make adolescents participating in learning have increased life satisfaction through cognitive facet. Within education system, emotional intellgence can be taught using collaborative curicullum (Smith, 2005). Kong et al. (2019) added that in adolescence, emotional intelligence that is more mature and formed can be caused by a large factor of social support from family, peers, and school. Emotional intelligence that has a greater share than general intelligence (IQ) begins in adolescence.

Studies with adolescent and adult samples both distinguish that emotional intelligence influences cognitive facets of life satisfaction through resilience (Liu, Wang, \& Lu, 2013) and expectations at work (Umphrey \& Sherblom, 2017). Being resilient can evoke positive emotions and suppress negative emotions when the individual is working and facing stress, which automatically increases the ability to regulate emotions (Apriani \& Listiyandini, 2019). Expectations at work and future goals are also closely related to the synergy between one individual and another, both in how to understand the emotional condition of other individuals and how to regulate one's own emotions when working. In addition, there are other factors that often affect the relationship between emotional intelligence and life satisfaction. The social support variable proved empirically to mediate the relationship between emotional intelligence and life satisfaction. Individuals with a high level of emotional intelligence tend to have many social networks that can lead to their welfare (Kong et al., 2019). Even so, the type of relationship that occurs is partially mediated, and although social support is proven to mediate emotional intelligence and life satisfaction, there is still a linear relationship between emotional intelligence and life satisfaction.

Egger's test regression result is greater than $p<0.05$, in both correcting method indicate that there is no publication bias. Even though this analysis using random effect model, using Hunter-Schmidt estimator the result is valid. This finding also underlined the theory, that the more emotionally intelligent individuals will have an increase in life satisfaction.

\section{CONCLUSION}

Meta-analysis shows that the correlation between emotional intelligence on life satisfaction is proven to be significant and positive. The range of confidence level of the correlation effect is around 0.280.41 for sampling corrected and $0.33-0.48$ for artifact measurement corrected. This fact is proven in cross-cultural studies and lifestyle. The application of two correction methods also shows results that are not far different. The conclusion is that emotional intelligence not only has an influence on how people succeed at work but also in individual life satisfaction. Like wisdom, emotional intelligence can be taught and understood at the age of adolescence as a provision at work, and emotional intelligence raises the level of life satisfaction.

\section{Suggestions}

There is at least two suggestion in this topic: 
1. Suggestion for further research is using the subgroups in participant. By adding multigroups, the result can be more accurate.

2. The author also can follow recommendation using Bayesian meta analysis for small dataset which is very often in research. Another advantages bayesian approach allow researcher to integrate the prior knowledge and thereby superior in estimating the heterogenity data and effect.

3. In the broader range, suggestion for stakeholder and government is to pay more attention in emotional intelligence. This can be done with creating or adding up new curriculum to promote emotional intelligence in it.

\section{REFERENCE}

Aguinis, H., Sturman, M. C., \& Pierce, C. A. (2008). Comparison of three meta-analytic procedures for estimating moderating effects of categorical variables. Organizational Research Methods, 11(1), 934.

Ahuja, A. (2011). Impact of Emotional Intelligence on performance of Call Centers Executives. IJRFM, Vol. 01, Issue 5 (ISSN 2231-5985).

Aksayli, N. D., Sala, G., \& Gobet, F. (2019). The cognitive and academic benefits of Cogmed: A meta-analysis. Educational Research Review, 29, 243. doi:https://doi.org/10.1016/j.edurev.2019.04.003

Alavi, M., Mehrinezhad, S. A., Amini, M., \& Parthaman Singh, M. (2017). Family functioning and trait emotional intelligence among youth. Health psychology open, 4(2), 2055102917748461. doi:10.1177/2055102917748461

Apriani,F. \& Listiyandini,R,A. (2019). Kecerdasan emosi sebagai prediktor resiliensi psikologis pada remaja di panti asuhan. Persona: Jurnal Psikologi Indonesia, 08(02), 325 - 339.

Bar-On, R. (2010). Emotional intelligence: an integral part of positive psychology. South African Journal of Psychology, 40(1), 54-62.

Beauvais, A.M., Brady, N., O'Shea, E.R., Griffin, M.T.Q., 2011. Emotional intelligence and nursing performance among nursing students. Nurse Educ. Today 31(4), 396-401. http://dx.doi.org/10.1016/j.nedt.2010.07.013.

Borenstein, M., Higgins, J. P., Hedges, L. V., \& Rothstein, H. R. (2017). Basics of meta-analysis: I2 is not an absolute measure of heterogeneity. Research synthesis methods, 8(1), 5-18.

Carvalho, V. S., Guerrero, E., \& Chambel, M. J. (2018). Emotional intelligence and health students' well-being: A two-wave study with students of medicine, physiotherapy and nursing. Nurse education today, 63, 35-42.

Card, N. A. (2015). Applied meta-analysis for social science research. Guilford Publications.

Dahlke, J, A. \& Wiernick, B, M. (2019). psychmeta: An R Package for Psychometric Meta-Analysis. Applied Psychological Measurement, 43(5), 415-416. DOI: $10.1177 / 0146621618795933$

Di Fabio, A., \& Palazzeschi, L. (2009). Emotional intelligence, personality traits and career decision difficulties. International Journal for Educational and Vocational Guidance, 9(2), 135-146.

Di Fabio, A., \& Kenny, M. E. (2016). Promoting well-being: the contribution of emotional intelligence. Frontiers in psychology, 7, 1182. 
Diener, E., Biswas-Diener, R. (2008). Happiness. Unloking the Mysteries of psychologival Wealth, Blackwell Publishing.

Diener, M. J., Hilsenroth, M. J., \& Weinberger, J. (2009). A primer on meta-analysis of correlation coefficients: The relationship between patient-reported therapeutic alliance and adult attachment style as an illustration. Psychotherapy Research, 19(4-5), 519-526.

Disabato, D. J., Goodman, F. R., Kashdan, T. B., Short, J. L., \& Jarden, A. (2015). Different types of well-being? A cross- cultural examination of hedonic and eudaimonic wellbeing. Psychological Assessment, 28, 471-482.

Egger, M., Smith, G. D., Schneider, M., \& Minder, C. (1997). Bias in meta-analysis detected by a simple, graphical test. Bmj, 315(7109), 629-634.

Gallagher, E. N., \& Vella-Brodrick, D. A. (2008). Social support and emotional intelligence as predictors of subjective well-being. Personality and individual differences, 44(7), 1551-1561.

Goleman, D. (2005). Working with Emotional Intelligence. New York: Bantam Books.

Hahn, V. C., Frese, M., Binnewies, C., \& Schmitt, A. (2012). Happy and proactive? The role of hedonic and eudaimonic well-being in business owners' personal initiative. Entrepreneurship theory and practice, 36(1), 97-114.

Hak, T., Van Rhee, H. J., \& Suurmond, R. (2016). How to interpret results of meta-analysis. (Version 1.3) Rotterdam, The Netherlands: Erasmus Rotterdam Institute of Management. www.erim.eur.nl/researchsupport/meta-essentials/downloads

Hogan, M. J., Parker, J. D., Wiener, J., Watters, C., Wood, L. M., \& Oke, A. (2010). Academic success in adolescence: Relationships among verbal IQ, social support and emotional intelligence. Australian Journal of Psychology, 62(1), 30-41.

Higgins, J. P., Thompson, S. G., Deeks, J. J., \& Altman, D. G. (2003). Measuring inconsistency in meta-analyses. Bmj, 327(7414), 557-560.

Ignat, A. A., \& Clipa, O. (2012). Teachers' satisfaction with life, job satisfaction and their emotional intelligence. Procedia-Social and Behavioral Sciences, 33, 498-502.

Johnson,B,T. Mullen, B. \& Salas, E. (1995). Comparison of three major meta-analytic approaches. Journal of Applied Psychology, 80(1), 94-106

Koohbanani, S. E., Dastjerdi, R., Vahidi, T., \& Far, M. H. G. (2013). The relationship between spiritual intelligence and emotional intelligence with life satisfaction among Birjand gifted female high school students. Procedia-Social and Behavioral Sciences, 84, 314-320.

Kong, F., Zhao, J., \& You, X. (2012). Social support mediates the impact of emotional intelligence on mental distress and life satisfaction in Chinese young adults. Personality and Individual Differences, 53(4), 513-517.

Kong, F. Gong, X. Sajjad, S. Yang, K. \& Zhao, J. (2019). How is emotional intelligence linked to life satisfaction? The mediating role of social support, positive afect and negative afect. Journal of Happiness Studies, 20(8), 2733-2745 https://doi.org/10.1007/s10902-018-00069-4

Koydemir, S., Şimşek, Ö. F., Schütz, A., \& Tipandjan, A. (2013). Differences in how trait emotional intelligence predicts life satisfaction: The role of affect balance versus social support in India and Germany. Journal of Happiness Studies, 14(1), 51-66. 
Landa, A.J.M., Lopez-Zafra, E., Aguilar-Luzon Mdel, C., de Ugarte, M.F., 2009. Predictive validity of perceived emotional intelligence on nursing students' self-concept. Nurse Educ. Today 29(7), 801808. http://dx.doi.org/10.1016/j.nedt.2009.04.004.

Langan, D., Higgins, J. P., \& Simmonds, M. (2015). An empirical comparison of heterogeneity variance estimators in 12894 meta-analyses. Research synthesis methods, 6(2), 195-205.

Liu, Y., Wang, Z., \& Lü, W. (2013). Resilience and affect balance as mediators between trait emotional intelligence and life satisfaction. Personality and Individual differences, 54(7), 850-855.

MacCann, C., Jiang, Y., Brown, L. E., Double, K. S., Bucich, M., \& Minbashian, A. (2020). Emotional intelligence predicts academic performance: A meta-analysis. Psychological Bulletin, 146(2), 150.

Maddux, J. E. (2017). Subjective well-being and life satisfaction: an introduction to conceptions, theories, and measures. In Subjective Well-Being and Life Satisfaction (pp. 3-31). Routledge.

Mayer, J. D., Caruso, D. R., \& Salovey, P. (2000). Emotional Intelligence meets traditional standards for an intelligence. Intelligence, 27(4), 267-298.

Mikolajewicz, N., \& Komarova, S. (2019). Meta-analytic methodology for basic research: a practical guide. Frontiers in physiology, 10(203).

Mosier,C,I. (1943). On the reliability of a weighted composite. Psychometrika, 8(3), 161-168. https://doi.org/10.1007/BF02288700

Özsoy, E., Uslu, O., \& Öztürk, O. (2014). Who are happier at work and in life? Public sector versus private sector: A research on Turkish employees. International Journal of Recent Advances in Organizational Behaviour and Decision Sciences, 1(2), 148-160.

Parker J.D.A., Saklofske D.H., Wood L.M., Collin T. (2009) The Role of Emotional Intelligence in Education. In: Parker J., Saklofske D., Stough C. (eds) Assessing Emotional Intelligence. The Springer Series on Human Exceptionality. Springer, Boston, MA

R Core Team (2018) R: A Language and Environment for Statistical Computing. R Foundation for Statistical Computing, Vienna. https://www.R-project.org

Riley, R. D., Higgins, J. P., \& Deeks, J. J. (2011). Interpretation of random effects meta-analyses. Bmj, 342, d549. doi: https://doi.org/10.1136/bmj.d549

Ruiz-Aranda, D., Extremera, N., Pineda-Galán, C., 2013. Emotional intelligence, life satisfaction and subjective happiness in female student health professionals: the mediating effect of perceived stress. $J$. Psychiatr. Ment. Health Nurs, 21(2), 106-113.http://dx.doi.org/10.1111/jpm.12052.

Runcan, P. L., \& Iovu, M. B. (2013). Emotional intelligence and life satisfaction in Romanian university students: The mediating role of self-esteem and social support. Revista de cercetare si interventie sociala, 40, 137-148.

Salovey, P., \& Mayer, J. D. (1990). Emotional intelligence. Imagination, Cognition, and Personality, 9, 185- 211

Saricam, H., Celik, I., \& Coşkun, 1. (2015). The relationship between emotional intelligence, hope and life satisfaction in preschool preserves teacher. The international journal of research in teacher education, 6(1), 1-9.

Sedgwick, P. (2013). Meta-analyses: how to read a funnel plot. Bmj, 346. f1342 
Smith, R,E. (2005). Understanding sport behavior: A cognitive-affective processing systems approach. Journal of Applied Sport Psychology, 18(1), 1-27, DOI: 10.1080/10413200500471293

Sterne, J. A., Sutton, A. J., Ioannidis, J. P., Terrin, N., Jones, D. R., Lau, J., ... \& Tetzlaff, J. (2011). Recommendations for examining and interpreting funnel plot asymmetry in meta-analyses of randomised controlled trials. Bmj, 343, d4002.

Suleman, Q., Hussain, I., Syed, M. A., Parveen, R., Lodhi, I. S., \& Mahmood, Z. (2019). Association between emotional intelligence and academic success among undergraduates: A cross-sectional study in KUST, Pakistan. PloS one, 14(7), e0219468.

Umphrey, L. R., \& Sherblom, J. C. (2018). The constitutive relationship of listening to hope, emotional intelligence, stress, and life satisfaction. International Journal of Listening, 32(1), 24-48.

Varatharaj, V. \& Vasantha, S. (2012). Work life balances a source of job satisfaction an exploratory study on the view of women employees in the service sector. ZENITH International Journal of Multidisciplinary Research, 2(3).

Vevea, J, L. \& Coburn, K, M. (2015). Maximum-likelihood methods for meta-analysis: A tutorial using R. Group Processes \& Intergroup Relations, 18(3) 329-347. DOI: $10.1177 / 1368430214558311$

Wiernik, B. M., \& Dahlke, J. A. (2020). Obtaining unbiased results in meta-analysis: The importance of correcting for statistical artifacts. Advances in Methods and Practices in Psychological Science, $3(1), 94-123$.

Yiğit, R., Dilmaç, B. and M. E., Deniz, 2011, İş ve yaşam doyumu: Konya emniyet müdürlüğü alan araştırması. Polis Bilimleri Dergisi, 13(3), 1-18. 